\title{
Time dependence of the surface Fermi level of GaAs in atmosphere
}

I. Ohbu, M. Takahama, and H. Mizuta

Central Research Laboratory, Hitachi Ltd., 1-280 Higashikoigakubo, Kokubunji, Tokyo 185, Japan

(Received 5 January 1993; accepted for publication 31 March 1993)

This letter reports the time dependence of the surface Fermi level of GaAs grown by molecular-beam epitaxy and then exposed to atmosphere. The sheet resistance of sample structures for field effect transistors alternately increased, decreased, increased, and decreased to become nearly constant after about $500 \mathrm{~h}$. These changes correspond to the surface Fermi level varying between 0.3 and $0.7 \mathrm{eV}$ and finally settling $0.7 \mathrm{eV}$ above the valence band maximum. Comparison between annealed and unannealed samples with low-temperature-grown GaAs layers showed that the pinning of the surface Fermi level at $0.7 \mathrm{eV}$ above the valence band maximum is caused by arsenic antisite defects. The result supports the advanced unified defect model.

The surface Fermi level $\left(E_{f s}\right)$ of GaAs is pinned at specific energy levels in the band gap. For $n$-type GaAs the pinning level is $0.75 \mathrm{eV}$ above the valence band maximum $\left(E_{v b m}\right)$, and for $p$-type GaAs it is $0.5 \mathrm{eV}$ above $E_{v b m} \cdot{ }^{1}$ Although there are many reports on GaAs surface oxidation, ${ }^{2-7}$ there have been few studies of the way in which the surface Fermi level changes during the oxidation processes. Studying these oxidation processes under carefully controlled conditions, Landgren et al. ${ }^{2}$ have shown how oxygen exposure changes the surface Fermi level of newly cleaved GaAs (110). They found that the $E_{f s}$ for $n$-type GaAs exposed to oxygen changed nonmonotonically: at low levels for exposure $E_{f s} E_{v b m}$ decreased with increasing oxygen exposure, reaching a minimum value of $0.7 \mathrm{eV}$ at $10^{5} \mathrm{~L}$ (Torr $\times \mathrm{s}$ ) and then increased at higher exposure levels. For $p$-type GaAs, on the other hand, $E_{f s}-E_{v b m}$ increased monotonically with increasing oxygen exposure. For both $n$ - and $p$-type GaAs, the surface Fermi level was not constant even after an oxygen exposure of $10^{12} \mathrm{~L}$.

The conditions to which GaAs surfaces are exposed during the manufacture of semiconductor devices are very different from these kinds of experimental conditions. The purpose of the present study is to investigate variations of the surface Fermi level of GaAs exposed to atmosphere.

The samples used in this study shown schematically in Fig. 1 were grown by molecular-beam epitaxy (MBE). Undoped semi-insulating GaAs substrates with a $\langle 100\rangle$ axial orientation were used to grow sample structures for heterostructure insulated gate field effect transistors (FET). The Be-doped GaAs layers inserted between the Si-doped GaAs layers and the undoped GaAs buffer layers suppress the short-channel effect in FETs. ${ }^{8}$ The holes in the Be-doped $\mathrm{GaAs}$ layers were fully depleted. GaAs was grown at $1 \mu \mathrm{m} / \mathrm{h}$ with a Ga-to-As ${ }_{4}$ beam equivalent pressure ratio of 10 . When growing $\mathrm{Al}_{0.3} \mathrm{Ga}_{0.7} \mathrm{As}$ layers, the $\mathrm{Al}$ cell shutter was opened while the Ga cell temperature and As cell temperature were kept constant. The undoped GaAs showed $n$-type conductivity. The growth temperature for all layers other than the low-temperature-grown GaAs (LT-GaAs) of samples B and C was measured by an optical pyrometer and was $530^{\circ} \mathrm{C}$. The growth temperature for the LT-GaAs, ${ }^{9-14}$ which was measured by a thermocouple behind the $\mathrm{GaAs}$ substrates was $300^{\circ} \mathrm{C}$. After

growth, sample $\mathrm{C}$ was annealed at $530^{\circ} \mathrm{C}$ for $10 \mathrm{~min}$ under an $\mathrm{As}_{4}$ beam. After the samples were removed from the MBE chamber, their sheet resistance was evaluated by a SONOGAGE 300 (Tencor Instruments). A twodimensional device simulator ${ }^{15}$ was used to calculate the surface Fermi level from the sheet resistance. For this study, we defined the surface Fermi level as the Fermi level at the surface oxide/undoped GaAs interfaces or the LT$\mathrm{GaAs} /$ undoped GaAs interfaces. The electron mobility of $1100 \mathrm{~cm}^{2} / \mathrm{V} \mathrm{s}$, which was obtained by Hall measurements using a van der Pauw method for the samples, was used for the calculation.

Figure 2 shows the time-dependence of sheet resistance for the samples in atmosphere. The time dependencies observed for samples $\mathrm{A}$ and $\mathrm{C}$ are similarly complex, showing four regions: region $\mathrm{I}$, in which sheet resistance increases between 0 and $60 \mathrm{~min}$; region II, in which sheet resistance decreases between 60 and $300 \mathrm{~min}$; region III, in which sheet resistance again increases between 300 and $2000 \mathrm{~min}$; and region IV, in which sheet resistance again decreases after $2000 \mathrm{~min}$. For sample B, on the other hand, sheet resistance changes little with time.

The relationships between the sheet resistance and $E_{f s^{-}}$ $E_{v b m}$ are shown in Fig. 3 for surface oxide thicknesses rang-

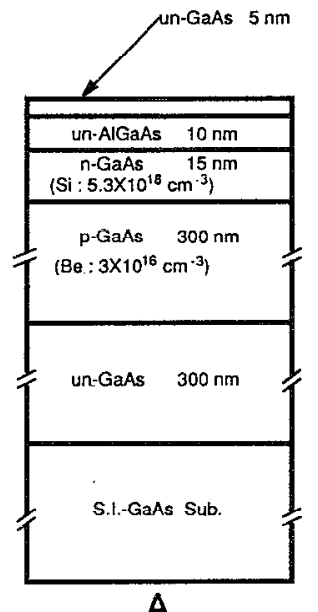

A

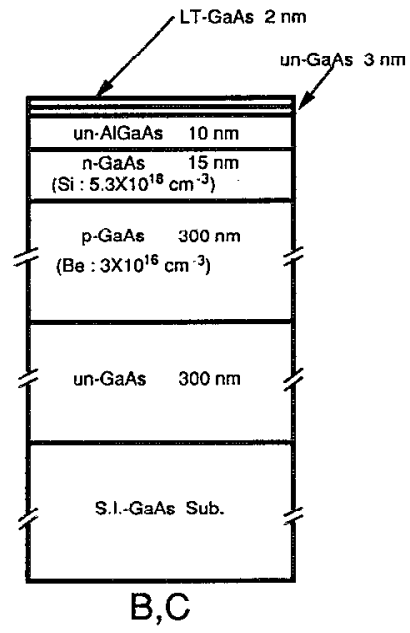

FIG. 1. Sample structures. 


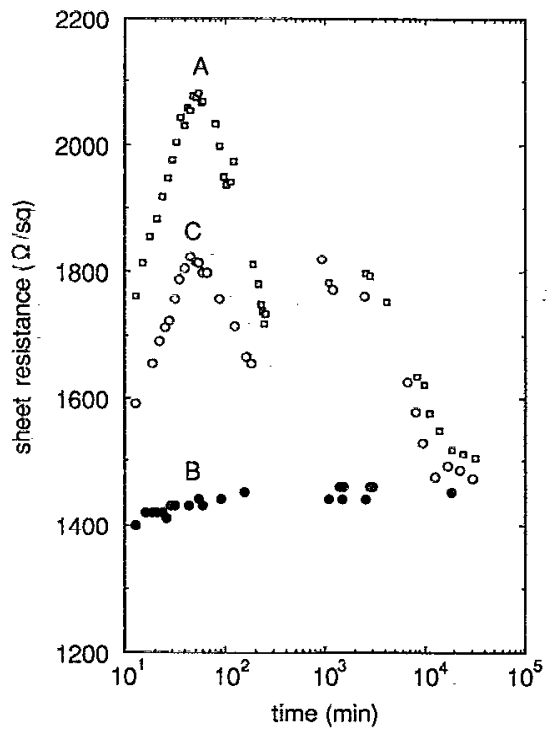

FIG. 2. Time dependence of sheet resistance after the samples are removed from the MBE chamber. Sample A ( $\square)$, sample B (๑), and sample $\mathrm{C}(\mathrm{O})$.

ing from 0 to $2 \mathrm{~nm}$. The actual thickness of the surface oxide in our samples, measured by spectroscopic ellipsometry at the end of the period during which sheet resistance was monitored, was $1.2 \mathrm{~nm}$ for samples $\mathrm{A}$ and $\mathrm{C}$ and 1.4 $\mathrm{nm}$ for sample $\mathrm{B}$. There are two possible causes for the sheet resistance increases shown in Fig. 2: one is the increase of the surface-oxide thickness and the other is a drop of the surface Fermi level. In region I of sample A, the sheet resistance increases from 1750 to $2100 \Omega / \square$. The increase of the surface-oxide thickness from 0 to $1.4 \mathrm{~nm}$, can explain only $150 \Omega / \square$ of the sheet resistance increase. Regions II and IV show decreases in sheet resistance, and this is opposite the changes in sheet resistance that would be caused by the increasing thickness of the surface oxide. The time dependence changes in the sheet resistance of sample A must therefore be mainly attributed to variation of the surface Fermi level.

We can see from Fig. 3 that the $E_{f s}-E_{v b m}$ value for

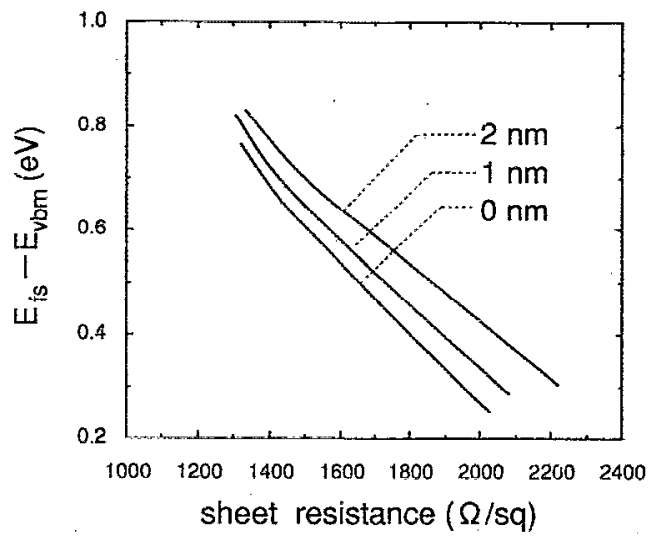

FIG. 3. Calculated relationships between surface Fermi level and sheet resistance for various thicknesses of surface oxide. sample A decreases to near $0.3 \mathrm{eV}$ at the end of region I. Although $E_{f s}-E_{v b m}$ increases in region II, in rcgion III it decreases again to about $0.5 \mathrm{eV}$, and finally, in region IV, $E_{f s}-E_{v b m}$ increases and becomes nearly constant at $0.7 \mathrm{eV}$. For sample B, on the other hand, $E_{f s}-E_{v b m}$ is about $0.75 \mathrm{eV}$ independent of the time in atmosphere. As-grown LTGaAs is known to contain arsenic antisite defects $\left(\mathrm{As}_{\mathrm{Ga}}\right)$ as many as $5 \times 10^{19} \mathrm{~cm}^{-3}, 16$ and these defects have double donor properties with the energy levels being located at $E_{v b m}-0.75 \mathrm{eV}\left(D^{0} / D^{+}\right)$and $E_{v b m}+0.52 \mathrm{eV}\left(D^{+} / D^{++}\right)$. Herc $D^{0}, D^{+}$, and $D^{++}$, respectively indicate the ionic charge states of $\mathrm{As}_{\mathrm{Ga}}^{3+}, \mathrm{As}_{\mathrm{Ga}}^{4+}$, and $\mathrm{As}_{\mathrm{Ga}}^{5+} \cdot{ }^{17}$ Sample $\mathrm{C}$, which was annealed at $530^{\circ} \mathrm{C}$ for $10 \mathrm{~min}$ under an $\mathrm{As}_{4}$ beam, shows a time dependence of sheet resistance similar to that of sample A. It has been known that hightemperature annealing of LT-GaAs decreases $\mathrm{As}_{\mathrm{Ga}}$ concentration by more than one order of magnitude. ${ }^{18}$ The surface Fermi level seems to be pinned firmly at the energy level of $\mathrm{As}_{\mathrm{Ga}}, 0.75 \mathrm{eV}$ above the valence band maximum, probably because of a high concentration of $\mathrm{As}_{\mathrm{Ga}}$ in this unannealed sample. The sheet resistance of sample $B$ is therefore independent of surface oxidation. This inference is supported by the time dependence of sheet resistance for sample $\mathrm{C}$, which has an $\mathrm{As}_{\mathrm{Ga}}$ concentration lower than that of sample $B$ and for which the pinning of the surface Fermi level therefore becomes weak. As the result, the surface Fermi level is affected by surface oxidation. The sheet resistances of samples $\mathrm{A}$ and $\mathrm{C}$ at the end of the region IV become constant at about $1500 \Omega / \square$, which corresponds to $E_{f s}-E_{v b m}=0.7 \mathrm{eV}$. This value is close to that of sample B. The surface Fermi level of GaAs thus seems to be pinned by $\mathrm{As}_{\mathrm{Ga}}$ at the end of surface oxidation processes. According to the advanced unified defect model (AUDM), ${ }^{18}$ the surface-pinning level of $n$-type GaAs is $0.75 \mathrm{eV}$ above the valence band maximum and the origin of the pinning is $\mathrm{As}_{\mathrm{Ga}}$. This pinning model is consistent with our results, but mechanisms responsible for the time dependence of the sheet resistance of GaAs exposed to atmosphere are not yet clear.

The behavior of the surface Fermi level reported here differs from that reported by Landgren et al. ${ }^{2}$ They found the surface Fermi level of $n$-type GaAs to show two regions as a function of oxygen exposure and the lowest Fermi level to be $0.7 \mathrm{eV}$ above the valence band maximum. This discrepancy between our results and those of Landgren et al. may be due to different oxidation processes. Although Landgren et al. used cleaved GaAs (110) in welldefined vacuum conditions, we studied GaAs (100) in atmosphere.

In conclusion, we have shown that there is a complex time dependence of the surface Fermi level of GaAs exposed to atmosphere: four regions are observed and the surface Fermi level varies between 0.3 and $0.7 \mathrm{eV}$ above the valence band maximum. Comparison with LT-GaAs shows that the pinning of the surface Fermi level at $0.7 \mathrm{eV}$ above the valence band maximum is caused by $\mathrm{As}_{\mathrm{Ga}}$ defects, and these results support the AUDM theory.

We thank I. Onodera for measuring of the surface oxide thickness by spectroscopic ellipsometry. 
${ }^{1}$ W. E. Spicer, P. W. Chye, P. R. Skeath, C. Y. Su, and I. Lindau, J. Vac. Sci. Technol. 16, 1422 (1979).

${ }^{2}$ G. Landgren, R. Ludeka, Y. Jugnet, J. F. Morar, and F. J. Himpsel, J. Vac. Sci. Technol. B 2, 351 (1984).

${ }^{3}$ F. Bartels, L. Surkamp, H. J. Clemens, and W. Monch, J. Vac. Sci. Technol. B 1, 756 (1983).

${ }^{4}$ C. Y. Su, I. Lindau, P. W. Chye, P. R. Skeath, and W. E. Spicer, Phys. Rev. B 25, 4045 (1982).

${ }^{5}$ K. A. Bertness, J. J. Yeh, D. J. Friedman, P. H. Mahowald, A. K. Wahi, T. Kendelewicz, I. Lindau, and W. E. Spicer, Phys. Rev. B 38, 5406 (1988).

${ }^{6}$ P. Kraus, W. N. Rodrigues, and W. Monch, Surf. Sci. 219, 107 (1989).

${ }^{7} \mathrm{~K}$. Tone, M. Yamada, Y. Ide, and Y. Katayama, Jpn. J. Appl. Phys. 31, L721 (1992).

${ }^{8} \mathrm{~K}$. Yamasaki, N. Kato, and M. Hirayama, IEEE Trans. Electron Devices FD-32, 2420 (1985).

${ }^{9}$ F. W. Smith, A. R. Calawa, C. L. Chen, M. J. Manfra, and L. J. Mahoney, IEEE Electron Device Lett. 9, 77 (1988).

${ }^{10}$ B. J. Lin, C. P. Kocot, D. E. Mars, and R. Jaeger, IEEE Trans. Electron Devices 37, 46 (1990).

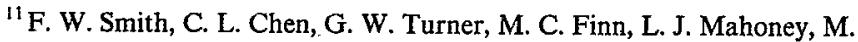
J. Manfra, and A. R. Calawa, Proceedings of the IEEE International Electron Devices Meeting (IEEE, New York, 1988), p. 838 .

${ }^{12}$ M. Kaminska, E. R. Weber, Z. L. Weber, R. Leon, and Z. U. Rek, J. Vac. Sci. Technol. B 7, 710 (1989).

${ }^{13}$ A. C. Warren, J. M. Woodall, J. L. Freeouf, D. Grischkowsky, D. T. Mcintuff, M. R. Melloch, and N. Otsuka, Appl. Phys. Lett. 57, 1331 (1990).

${ }^{14}$ I. Ohbu, M. Takahama, and K. Hiruma, Appl. Phys. Lett. 61, 1679 (1992).

${ }^{15}$ H. Mizuta, K. Yamaguchu, M. Yamane, T. Tanoue, and S. Takahashi, IEEE Trans. Electron Devices 36, 2307 (1989).

${ }^{16}$ M. Kaminska, Z. L. Weber, E. R. Weber, T. George, J. B. Kortright, F. W. Smith, B. Y. Tsaur, and A. R. Calawa, Appl. Phys. Lett. 54, 1881 (1989).

${ }^{17}$ E. R. Weber, H. Ennen, U. Kaufman, J. Windscheif, J. Schneider, and T. Wosinski, J. Appl. Phys. 53, 6140 (1982).

${ }^{18}$ W. E. Spicer, Z. Liliental-Weber, E. Weber, N. Newman, T. Kendelewicz, R. Cao, C. McCants, P. Mahowald, K. Miyano, and I. Lindau, J. Vac. Sci. Technol. B 6, 1245 (1988). 